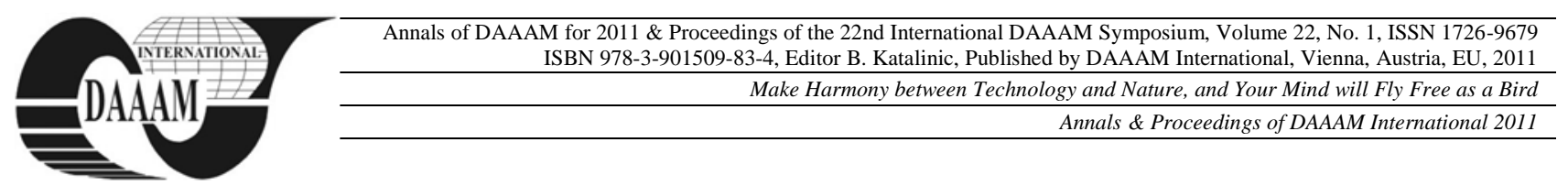

\title{
IN DEFECTS DIAGNOSTICS BY USING NDT METHODS AND THEIR IMPACT ON REMAINING LIFE
}

\author{
MARTANCIK, B[ranislav]; MARTANCIKOVA, G[abriela]; ULRICH, K[oloman] \& BARTA, J[ozef]
}

\begin{abstract}
Abstract Nowadays a great accent lies in the quality control of weld joints. Presence of the defects in weld joints and incorrect diagnostics usually causes the collision and the crash of welded constructions. The paper deals with the comparison of results obtained by the ultrasonic techniques, TOFD and Phased Array with the classical radiography method. The differences in defect size determined by various methods lead to different results determining the residual life of welded construction.
\end{abstract}

Key words: defect, non-destructive testing, TOFD, phased array, welded joint, remaining life

\section{INTRODUCTION}

The new NDT methods are capable of obtaining the full view of the shape, size and position of the defect in examined material, whereas in the standard NDT methods it is necessary to compare the results with reference standards and dependent on user skills. To designation of the residual lifetime of the welded constructions, it is necessary to have complex knowledge about present defects (Kováčik \& Hyža, 2009). These data can be obtained using computer-aided ultrasonic inspection techniques TOFD and Phased Array. The main objective was to compare the results of weld joints quality control using above mentioned methods on samples having defects produced on purpose. The difference in measurements obtained by both control methods leads to different determination of residual lifetime of welded construction containing the defects (Kopec 2008).

\section{METHODS}

TOFD is an ultrasonic method allowing the detection of cracks dimensions and their position in relation to the surface of the material. The method is based on ultrasonic wave diffraction on defect peaks. Two probes are used for detection. The first probe works as a transmitter whereas the second one works as the receiver. The position of both probes is registered by the encoder. Vertical dimension of the crack is calculated by the principle of the Pythagorean Theorem. The data used for calculation are the time difference between arriving waves reflected from the upper and lower edge of the crack, velocity of the ultrasound propagation in examined material and the distance between the probes (Kováčik \& Hyža, 2010).

Phased Array (PA) method use ultrasonic probes with maximum of 126 array elements for testing, that allows sound distribution without necessity of probe movement in the perpendicular direction of the weld joint axis on the material surface. The phased transducer excitation enables ultrasonic beam deflection, focus and sound distribution by contemporary transmission of the beam in the angles of $45^{\circ}, 60^{\circ}$ a $70^{\circ}$. The detection of various oriented cracks was very difficult using conventional ultrasonic method but the PA method brings high accuracy into the measurement (Ulrich \& Martančík \& Martančíková, 2011).

The material used in experimental was S355 steel sheet. Two samples were welded by GMAW technology in $\mathrm{CO}_{2}$ protective gas. A butt weld of double $\mathrm{V}$-shaped groove was performed on both samples however the first sample (Sample 1) was $25 \mathrm{~mm}$ in thickness and the second one (Sample 2) was $31 \mathrm{~mm}$ thick welded as single V-shaped butt weld. In both weld joints were defects produced on purpose in order to compare the sensitivity of current High-tech ultrasonic methods (TOFD and Phased Array) and radiography method.

Omniscan device with the probes of $5 \mathrm{MHz}$ frequency were used for the control carried out by TOFD method, whereby the distance between both probes in case of Sample 1 was set to $60 \mathrm{~mm}$ and $70 \mathrm{~mm}$ in case of Sample 2. Sample 1 was analysed three times with the parameters of 34,40 and $46 \mathrm{~dB}$. Figure 1 shows the experimental set-up of probes and wave path through the sample. The parameters in case of Sample 2 TOFD measurement were 45,51 and $57 \mathrm{~dB}$.

The probe containing 16 transducers of $2 \mathrm{MHz}$ was used within the Phased Array method. The sound was distributed through the material in the angle range from $45^{\circ}$ to $70^{\circ}$ in dependence on probe position from the weld axis. The sensitivity of this method was calibrated on reference standard with the hole of $1.5 \mathrm{~mm}$ in diameter and $21 \mathrm{~mm}$ in depth for the echo size with the maximum of $80 \%$ screen appearance (FSH). Figure 2 shows the experimental set-up of the probe in relation to the weld position.

A lot of defects observed in Sample 1 were situated in the root section (figure 3 ) of the weld joint (11 to $14 \mathrm{~mm}$ ) since as it is double-sided $\mathrm{V}$-shaped weld joint. The record also provides the information on dimensions of defects obtainable by the TOFD detection method.

Figure 4 demonstrates defects and measurements of their dimensions on Sample 2. All defects were observed at the back wall of the sample, what represents the root section of the weld in case of single-side V-shaped butt weld.

Phased Array control measurement of Sample 1 is shown in figure 5 together with the measurement of defect size.

Defects presented in Sample 2 are shown in figure 6. Based on the measurement results were defects identified as poruses and their clusters. These defects are not considered as the fracture initiators and their size do not influence directly residual lifetime of welded construction. That is why the Sample 2 absents the measured values in Table 2 as well as the residual lifetime calculations.

The particular ultrasonic methods offered slightly different values in measurements of the defects. The defects dimensions measured on Sample 1 and Sample 2 by both TOFD and Phased Array methods are provided in Table 1.

The ultrasonic methods of TOFD and Phased Array currently belong to the new methods of non-destructive testing verified by the practice. 


\begin{tabular}{|c|c|c|c|c|c|}
\hline \multirow{2}{*}{$\begin{array}{c}\text { No. of } \\
\text { sample }\end{array}$} & \multirow{2}{*}{$\begin{array}{c}\text { No. of } \\
\text { error }\end{array}$} & \multicolumn{2}{|c|}{ TOFI } & \multicolumn{2}{c|}{ Phased Array } \\
\cline { 3 - 6 } & $\begin{array}{c}\text { Error } \\
\text { length } \\
{[\mathrm{mm}]}\end{array}$ & $\begin{array}{c}\text { Error } \\
\text { depth } \\
{[\mathrm{mm}]}\end{array}$ & $\begin{array}{c}\text { Error } \\
\text { length } \\
{[\mathrm{mm}]}\end{array}$ & $\begin{array}{c}\text { Error } \\
\text { depth } \\
{[\mathrm{mm}]}\end{array}$ \\
\hline $\mathbf{1 .}$ & $\mathbf{1 .}$ & 18.50 & 6.43 & 5 & 9.50 \\
\hline $\mathbf{1 .}$ & $\mathbf{2 .}$ & 297 & 3.75 & 26.50 & 2.57 \\
\hline $\mathbf{2 .}$ & $\mathbf{1 .}$ & 23 & 1.03 & $\mathrm{x}$ & $\mathrm{x}$ \\
\hline $\mathbf{2 .}$ & $\mathbf{2 .}$ & 15.50 & 0.81 & $\mathrm{x}$ & $\mathrm{x}$ \\
\hline $\mathbf{2 .}$ & $\mathbf{3 .}$ & 40.50 & 1.01 & $\mathrm{x}$ & $\mathrm{x}$ \\
\hline
\end{tabular}

Tab 1. Defects dimensions measured in Sample 1

Based on the material, its thickness and shape, it is desirable to verify the measurements results especially the reproducibility of tests and sensitivity for particular application. The measurements results of conventional radiographic method for both Sample 1 and Sample 2 are provided in Figure 7 and Figure 8.

According to the radiography control results it can be claimed, that in case of the Sample 1 weren't observed any distinct defects in weld joint, except for the face undercut defects detected by previously used visual inspection. The record of Sample 2 did not clearly identify the presence of defects what indicates the possible acceptance of weld joint from the quality point of view.

Based on determined dimensions and the defects type present in the weld joints, it is possible to calculate residual lifetime of welded construction during the fatigue crack growth incipient from these defects (material S355, Re $=345 \mathrm{MPa}$, $\mathrm{KIC}=58 \mathrm{MPa} \sqrt{\mathrm{m}})$. The number of cycles till the construction failure $(\Delta \mathrm{N})$ in Sample 1 is very different due to the dimensions of the $2^{\text {nd }}$ defect (Table 1) measured by both Phase Array and TOFD methods. The immediate defect size of $2.57 \mathrm{~mm}$ observed by Phased Array method corresponds with $1.186 \times 10^{6}$ cycles. The measurement of the same defect by TOFD method showed $3.75 \mathrm{~mm}$ in depth what correspond to 780460 cycles till the construction failure. Defect No.1 present in Sample 1 showed dimensions exceeding the defect length in the lifetime end. Therefore the calculations of cycle's number difference were not perfected.

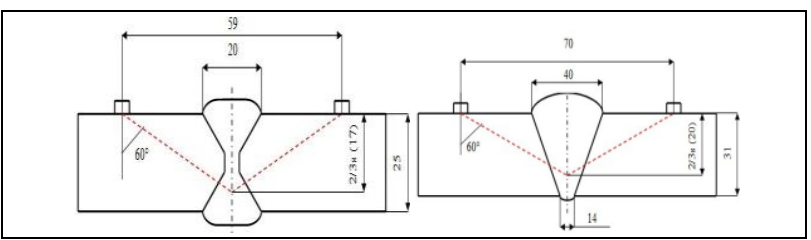

Fig. 1. Set-up of probes for TOFD testing

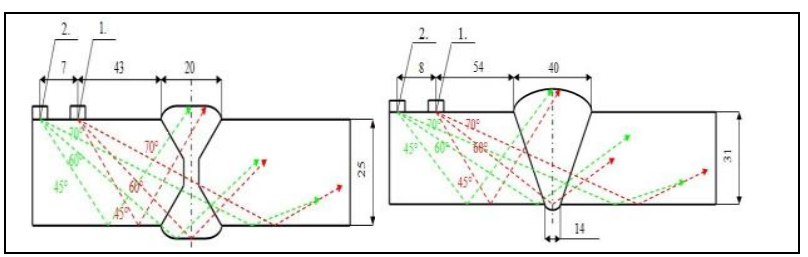

Fig. 2. The experimental set-up for Phased Array method

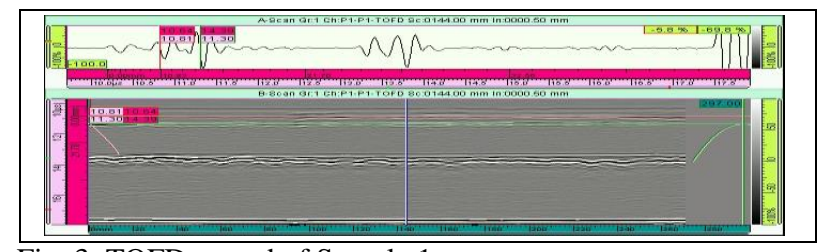

Fig. 3. TOFD record of Sample 1

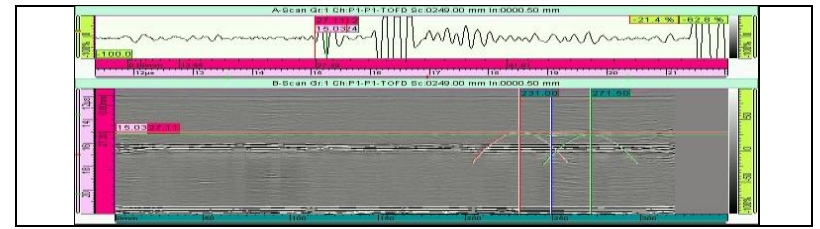

Fig. 4. TOFD record of Sample 2

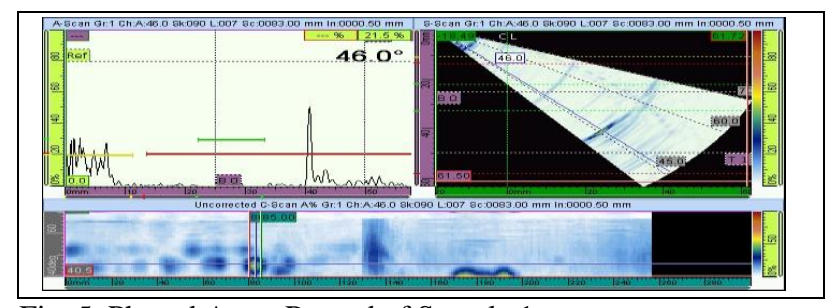

Fig. 5. Phased Array Record of Sample 1

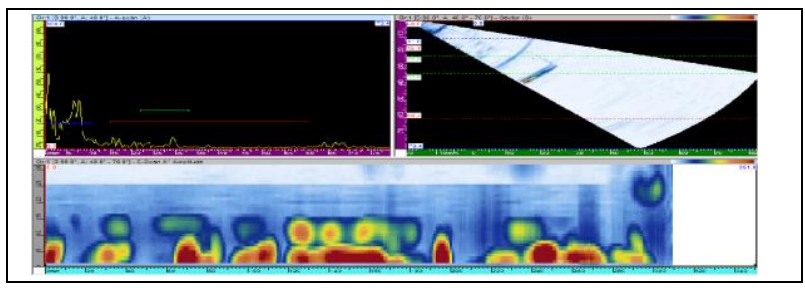

Fig. 6. Phased Array record of Sample 2

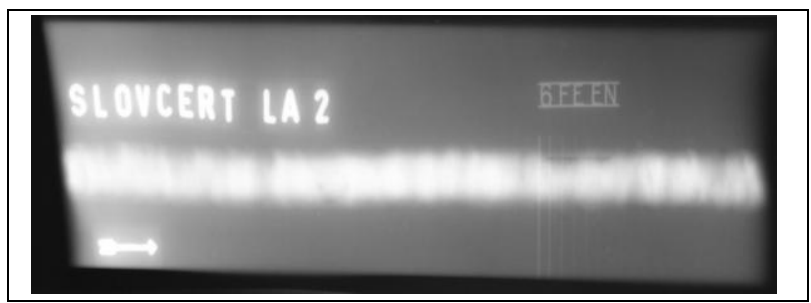

Fig. 7. Record of weld sample No. 1 by radiography method

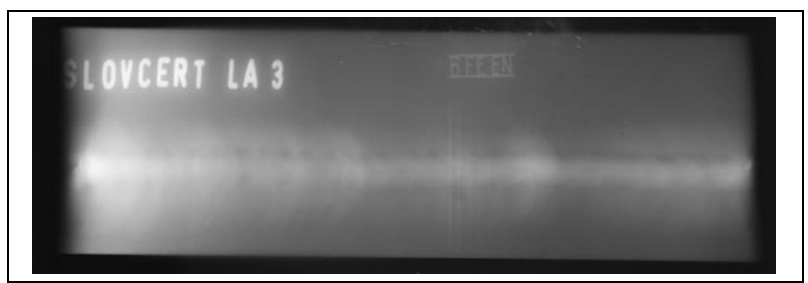

Fig. 8. Record of weld sample No. 2 by radiography method

\section{CONCLUSION}

Regarding the comparison of residual lifetime calculations of welded construction it can be concluded that the defect detected by the TOFD revealed less cycles to the failure than Phased Array. The limit state of the construction failure could be reached untimely when using the Phased Array method showing the higher number of cycles and therefore it is recommended to use TOFD method showing less cycles from the safety point of view. These differences in cycle number are caused by the measurements in different angles of ultrasound waves according to particular method. The reliability of each method is still an important subject of research, demanding a lot of testing and evaluation from manufacturer's side.

\section{REFERENCES}

Kováčik, M.; Hyža, R. (2009). Techniques for testing welds by ultrasound and their acceptability criteria. http://www.slovcert.sk Accessed on: 2011-05-13

Ulrich, K.; Martančík, B.; Martančíková, G. (2011). Verification of the sensitivity of ultrasound techniques with radiography method on samples with a thickness of $25 \mathrm{~mm}$. Welder (Zvárač), Vol. 8, No. 2, (06. 2011), pp. 18-21, ISSN 1336-5045.

Kopec, B. (Brno 2008) Non-destructive testing of materials and structures. ISBN 978-80-7204-591-4

Kováčik, M.; Hyža. R. (2010). TOFD ultrasonic technique to determine the depth scale errors. http://www.slovcert.sk Accessed on: 2011-03-23 